\title{
The magnetic fabrics of experimentally deformed artificial clay-water dispersions
}

\author{
Carl Richter ${ }^{\mathrm{a}}$, Wolfgang Frisch ${ }^{\mathrm{b}}$, Lothar Ratschbacher ${ }^{\mathrm{b}}$ and Hans-Ulrich Schwarz ${ }^{\mathrm{c}}$ \\ a Department of Geological Sciences, University of Michigan, Ann Arbor, MI 48109, USA \\ ${ }^{b}$ Institut für Geologic, Universität Tübingen, D-7400 Tübingen, Germany \\ ' Institut für Geologie, Universität Bochum, D-4630 Bochum, Germany
}

(Received March 7, 1991; revised version accepted August 13, 1991)

\begin{abstract}
Richter, C., Frisch, W., Ratschbacher, L. and Schwarz, H.-U., 1991. The magnetic fabrics of experimentally deformed clay-water dispersions. Tectonophysics, 200: 143-155.

The development of magnetic fabrics in artificial clay-water dispersions and natural, hematite-bearing mudstones is investigated in plane-strain pure shear laboratory experiments under strain rates of $1.6 \times 10^{-5}$ and $2 \times 10^{-4} \mathrm{~s}^{-1}$. The mixtures contain $0,15,30$ and $45 \%$ chlorite in an illite matrix, and $0,1,3,6$ and $8 \%$ magnetite in a kaolin matrix. Shortening up to $40 \%$ is imposed. The resulting fabrics show the following characteristics: (1) In the clay mixtures, the principal susceptibility axes $\left(k_{\max } \geq k_{\text {int }} \geq k_{\min }\right.$ ) rotate away from the well defined initial fabric orientations into the principal strain directions $\left(e_{1} \geq e_{2} \geq e_{3}\right)$ at strains $>30 \%$. (2) Both mineralogical composition and initial magnetic fabric, but not the applied strain, influence the magnitudes of the principal susceptibility axes. (3) The illite-chlorite mixture series show an almost linear correlation between mineral concentration and susceptibility magnitudes. (4) Magnetite dominates the fabric of the magnetite-kaolin mixtures; the fabric is independent of the magnetite concentration.
\end{abstract}

\section{Introduction}

The anisotropy of magnetic susceptibility (AMS, magnetic fabric) is represented by a second rank tensor and is visualized by an ellipsoid. The magnitude of magnetization $(M)$ is a function of the magnetic field strength $(H)$ :

$M_{i}=k_{i j} H_{j}$

where $k_{i j}$ is the magnetic susceptibility tensor (e.g., Hrouda, 1982; Nye, 1985).

The principal directions of the magnetic fabric have been shown to correlate with the principal axes of strain in deformed rocks (e.g., Kligfield et al., 1982; Pearce and Fueten, 1989), and laboratory experiments (Owens and Rutter, 1978; Borradaile and Alford, 1988; Borradaile and $\mathrm{Pu}$ umala, 1989). Field studies carried out in areas of homogeneous lithology proposed a one to one correspondence between the magnitudes of strain and the magnitudes of the AMS (e.g., Rathore,
1979, 1980; Hirt, 1986; Ruf et al., 1988). Universally valid correlation factors, however, do not appear to exist (Borradaile and Mothersill, 1984; Borradaile, 1988). Recent investigations demonstrated marked dependence of magnetic fabrics on the mineralogical composition (Borradaile et al., 1987; Borradaile, 1987), that may obliterate and overprint strain induced AMS.

Magnetic fabrics of undeformed sediments and igneous rocks were attributed to sedimentary or volcanic processes (e.g., Channel et al., 1979; Ellwood, 1982; Schieber and Ellwood, 1988), and to tectonic processes in deformed rocks. Intermediate stages exist where both primary and secondary tectonic fabrics constitute the total fabric (e.g., Borradaile and Tarling, 1981; Kligfield et al., 1981; Kissel et al., 1986). The interactions between the AMS of a sediment, variations in the mineral composition, and the effects of the first stages of deformation on the initial fabric is a topic of general interest since many sedimentary 
rocks and soft ocean floor muds of large-scale compressional zones (e.g., Bengal fan - Curray et al., 1979; coastal range Taiwan - Kissel et al., 1986) are weakly deformed and criteria are needed to decide whether the magnetic fabric is strain induced or still of primary depositional origin. A number of studies (e.g., Crimes and Oldershaw, 1967; Rees et al., 1968; Hamilton and Rees, 1971) have investigated the relationship between the direction of sediment transport and the orientation of magnetic fabrics. The shape of the AMS ellipsoid was used to determine influences of deformation on these primary fabrics (Crimes and Oldershaw, 1967; Rees et al., 1968). The proposed values and limits, however, do not take into account the strong influences of the mineral composition on the AMS (Borradaile et al., 1987; Borradaile, 1987) and cannot therefore be regarded as universally diagnostic criteria. Kissel et al., (1986), using samples of marine clays from northwest Greece and Taiwan, demonstrated that in the early stages of deformation the $k_{\text {max }}$ axes are aligned perpendicular to the direction of maximum shortening, but the $k_{\min }$ axes remained perpendicular to bedding, still marking the depositional fabrics. Many natural, soft, and lithified pelites include mixtures of chlorite, illite, kaolinite, quartz, and magnetite. About $30 \%$ of the ocean-floor sediments consist of pelagic clays, and despite slow sedimentation rates about $15 \%$ of all sedimentary rocks are pelagic clays (Chilingarian, 1981).

The purpose of this study is to examine under experimental conditions the relationships between the anisotropy of magnetic susceptibility, mineralogical composition, and strain in weakly deformed clay-water dispersions. The aim is to derive criteria for the interpretation of soft sediment anisotropy data in terms of finite strain. Since natural samples with exactly identical initial fabric deformed with varying strain magnitudes do not exist, we used samples with varying initial fabrics for each step of the deformation experiments.

The orientations of the principal susceptibility axes are presented in lower hemisphere equal area stereograms following the conventions proposed by Ellwood et al., (1988), were $k_{\text {max }}$ direc- tions are represented by squares, $k_{\text {int }}$ directions by triangles, and $k_{\min }$ directions by circles. The magnitudes and ellipsoid shapes of the principal susceptibilities are visualized in Flinn diagrams commonly used in strain representation (Flinn 1962). The parameters used to express the magnitude properties of the susceptibility ellipsoid are the degree of anisotropy $P=k_{\max } / k_{\min }$, and the parameters $F=k_{\text {int }} / k_{\min }$ and $L=k_{\max } / k_{\text {inl }}$, the magnetic foliation and lineation (e.g., Jelinek, 1981; Hrouda, 1982). Strain is expressed as the elongation $e$ in percent, which is the ratio of the relative change of the length of a line $(\Delta l)$ with the initial length $(l)$ of the line $(e=100 \Delta l / l)$. Since only plane strain deformations under pure shear conditions were carried out, the amount of shortening $e_{3}$ corresponds to the amount of extension $e_{1}$.

\section{The artificial samples}

\section{The materials}

The artificial samples were prepared from illite, chlorite, and magnetite obtained from Ward's (Ward's Natural Science Establishment, Inc., New York). In addition, we used a crushed natural Keuper mudstone from the European continental Triassic ("Knollenmergel", southwest Germany) and an industrial kaolin clay, a kaolinite bearing mixture of different clay minerals. The mean bulk susceptibility of illite is $108.9 \times 10^{-6} \mathrm{SI} /$ unit volume (volume susceptibility in SI units is used throughout the study). We powdered the material in a laboratory mill and obtained a material size of 20-60 $\mu \mathrm{m}$. The chlorite is a mineral aggregate with a bulk susceptibility of $795.6 \times 10^{-6}$. It was powdered and sieved and size fractions between 60 and $125 \mu \mathrm{m}$ were obtained. The magnetite fraction was obtained from crushed and powdered crystal aggregates. The Keuper clay is a red lithified mudstone with a bulk susceptibility of $75.0 \times 10^{-6}$. The material was powdered in a mill after drying three days at $100^{\circ} \mathrm{C}$. The unsieved substance consists of quartz, clay, and a silt sized fraction of quartz and clay aggregates up to 0.5 $\mathrm{mm}$ in diameter. The kaolin clay matrix, used to prepare the magnetite bearing samples, is a com- 
mercially available grey clay containing about $25 \%$ kaolinite, $45 \%$ illite, and $30 \%$ quartz with a bulk susceptibility of $36.1 \times 10^{-6}$.

\section{Sample preparation}

We mixed clay powders containing different amounts of illite, chlorite, kaolin, or magnetite with $30 \mathrm{wt} . \%$ water. The final mixtures had the consistency of a modeling clay. The water content was controlled after the deformation experiments by weighing, drying $\left(110^{\circ} \mathrm{C}, 24 \mathrm{~h}\right)$, and weighing once again. We prepared two mixture series, the first containing $1,3,6$, and $8 \mathrm{wt} . \%$ magnetite in a kaolin matrix and the second containing $0,15,30$, and $45 \mathrm{wt} . \%$ (referred to the dry substances) chlorite in an illite matrix. The powdered Keuper sediment and the kaolin clay were mixed with $30 \%$ water without additions. To obtain a reproducible initial clay fabric, first a random orientation of the mineral particles was imparted by kneading the mixtures by hand and machine. Then the soft clay matrix was placed into the middle of the mould of the deformation stage and spread by hand to the rims. After the approximate flattening of the clay, its surface was smoothed with a slat. The direction of smoothing, to produce the same initial orientation of the clay mixtures, was kept constant $\left(45^{\circ}\right.$ to the principal strain axes) for all samples. Micaceous microfabrics created in this way are characterized by subhorizontally oriented (001) mica lattice planes that are inclined against the smoothing direction (Schrader, 1970). Hence, the initial fabric was not random.

We attained about 150 undisturbed cylindrical specimens from the deformed and - for reference - undeformed clay mixtures for the magnetic measurements. Two specimens were taken from the clay after each deformation step.

The clay was positioned into oriented cylindrical plastic tubes of standard dimension $(2.5 \times 2.2$ $\mathrm{cm}$ ) by gently pressing them into the clay using electrolytical equipment (electro-osmosis; Chmelik, 1967) that cuts the clay dispersion without destroying the microfabric (Fig. 1). At the actual contact of the ring-shaped cathode the clay mud is fluidized by the electrolytical process. This

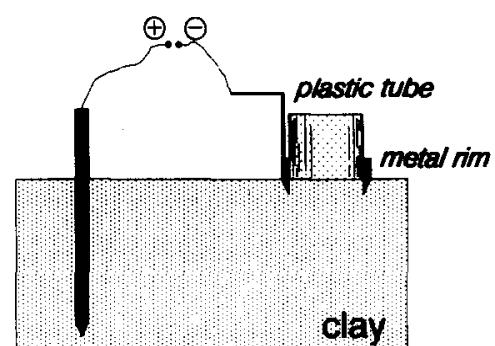

Fig. 1. The electrolytical procedure of the specimen preparation from the soft clay sample: the mud is fluidized at the actual contact of the metal ring, which allows the ring/plastic tube combination to sink into the mud without destroying the clayfabric; electro-osmotic cutting (Chmelik, 1967).

allows the metal ring/plastic tube set to sink into the mud. The open end of the clay filled and oriented plastic tubes was closed with an appropriately sized plastic disc. To prevent the material from shrinking due to water loss, the specimens were kept in a water saturated atmosphere until magnetic measurements were carried out.

\section{Experimental procedures}

\section{Plane strain experiments}

Plane-strain deformations under pure shear conditions were carried out on the "Big Bochum Deformation Stage" (Hoeppener et al., 1969; Hoeppener and Schwarz, 1980) at the University of Bochum. The device permits homogenous plane strain pure shear and simple shear deformations of soft substances at strain rates between $2 \times 10^{-3} \mathrm{~s}^{-1}$ and $4 \times 10^{-6} \mathrm{~s}^{-1}$. During straining the horizontal dimensions are continuously altered, one dimension being lengthened $\left(e_{1}\right)$ while the other is correspondingly shortened $\left(e_{3}\right)$ so that the surface area remains constant (i.e. constant volume deformation; Fig. 2). The sample is positioned in a latex lined trough (initial surface area $50 \times 50 \mathrm{~cm}$ ); the possible height of the sample is $0.5-5 \mathrm{~cm}$. The changes in length, the displacement of the trough rims, and the deformation of the basal area are controlled by four rails at the trough rims. Coaxial deformations result, if two of the rails are shifted parallel with electronically controlled velocities. The movement of the rails is transmitted by cubic sleeves at the base of 


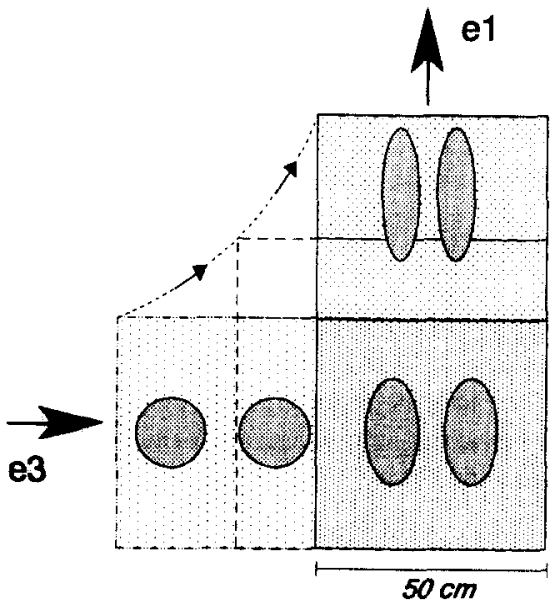

Fig. 2. The principle of the co-axial plane strain deformations. Small arrows indicate particle motion of the upper left corner, large arrows show compressional and extensional directions; circles and ellipses show initial, intermediate, and final shape of reference circles.

the stage which allows a homogeneous deformation of the total sample (compare figs. 2-5 of Hoeppener et al., 1969).

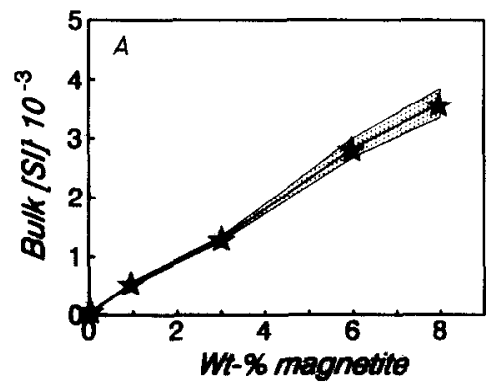

The clay mixtures were deformed at strain rates of $1.6 \times 10^{-5} \mathrm{~s}^{-1}$ and $2.0 \times 10^{-4} \mathrm{~s}^{-1}$ with shortening strains of $0,10,15,25,30$ and $40 \%$.

\section{Magnetic measurements}

Magnetic measurements were carried out at the paleomagnetic laboratory of the University of Leoben (Austria). The AMS was measured with a Digico anisotropy delineator. The $z$-axes susceptibilities were combined with the susceptibility differences to determine shapes and magnitude of the magnetic susceptibility ellipsoid. The results were recalculated according to the equations given by Hrouda et al., (1983). Acquisition curves of the isothermal remanent magnetization (IRM) were determined with a Förster fluxgate magnetometer and calibrated with a Digico spinner magnetometer. The magnetic field was produced using an electromagnet with field strength up to $1.5 \mathrm{~T}$.

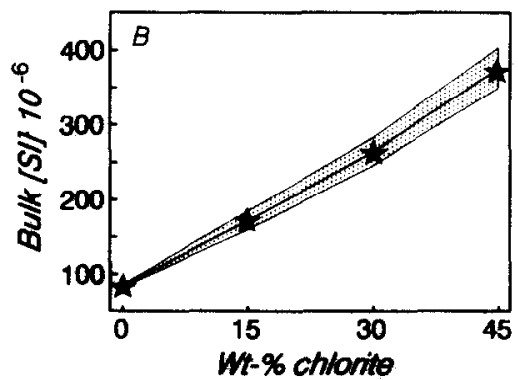

Fig. 3. Averaged bulk susceptibilities vs. mineral concentration of (A) magnetite-kaolin mixtures and (B) illite-chlorite mixtures. The stippled area indicates the standard deviation $2 \sigma$. Both curves are almost linear and indicate a simple two component mixture.
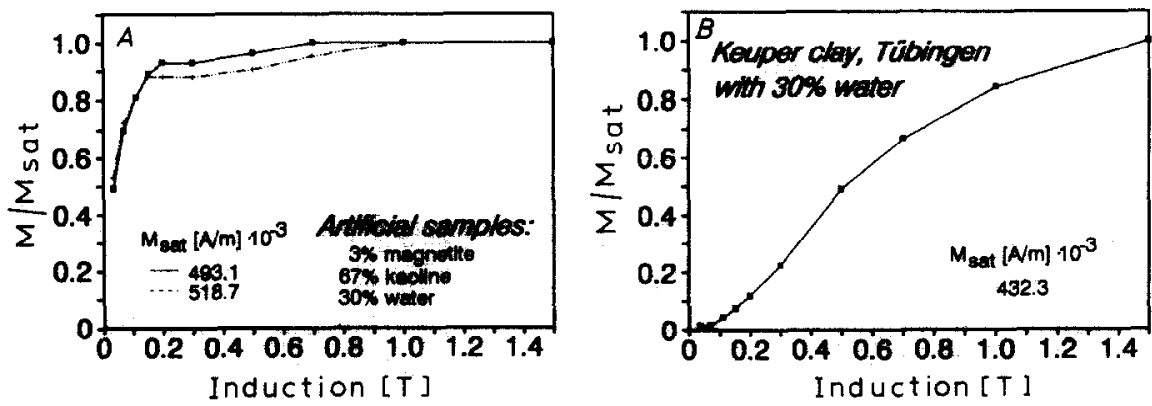

Fig. 4. Normalized acquisition curves of the isothermal remanent magnetization (IRM). (A) Results from two artificial magnetitekaolin specimens; saturation is reached in a $0.2 \mathrm{~T}$ field; depression suggests the presence of ferromagnetic hydroxides. (B) Typical hematite curve of the natural Keuper clay; saturation is not reached at $1.5 \mathrm{~T} . M_{\text {sat }}$ is the saturation magnetization. 


\section{Experimental results}

\section{Magnetic characteristics of the used materials}

The bulk volume susceptibility measurements showed an almost linear correlation between the mineral composition and the bulk susceptibility for the three component systems kaolin-magnetite-water and illite-chlorite-water (Fig. 3). The low scatter of the susceptibility magnitudes (see $2 \sigma$ area in Fig. 3) indicates considerable homogeneity of the mineral mixtures. To look closer at the saturation behavior of the magnetic carrier minerals, acquisition curves of the isothermal remanent magnetization (IRM) were obtained (Fig. 4). The artificial samples containing $3 \%$ magnetite reach $90 \%$ of their saturation magnetization at about $0.2 \mathrm{~T}$ applied field (Fig. 4A), a behavior that is typical for magnetite (e.g., Tarling, 1983; Mauritsch et al., 1987). The small depression of the IRM curves at about $0.3-0.4 \mathrm{~T}$ suggests the presence of ferromagnetic hydroxides, possibly originating from oxidation of magnetite in the clay-water dispersion. The magnetic mineral in the Keuper clay (Fig. 4B) is hematite indicated by the gentle slope of the acquisition curve and the fact that saturation of the isothermal remanent magnetization $\left(M_{\text {sat }}\right)$ was not reached at $1.5 \mathrm{~T}$ (Tarling, 1983; Mauritsch et al., 1987; Dekkers, 1988). The saturation magnetization of the magnetite bearing samples is about 0.5 $\mathrm{A} / \mathrm{m}$ and the achieved saturation of the Keuper clay is $0.43 \mathrm{~A} / \mathrm{m}$.

\section{The undeformed reference samples}

In Fig. 5A the principal susceptibility axes of the unstrained reference samples are shown in a stereogram orientated according to the geometry of the deformation stage (Fig. 2). The smoothing direction is indicated by the large arrow. The minimum susceptibility axes are subvertical, the maximum axes are oriented subparallel to the smoothing direction. The initial magnetic fabric, therefore, reflects the clay fabric introduced during sample preparation. The maximum susceptibility axis parallels the direction of smoothing, the initial extension direction, and the compres-

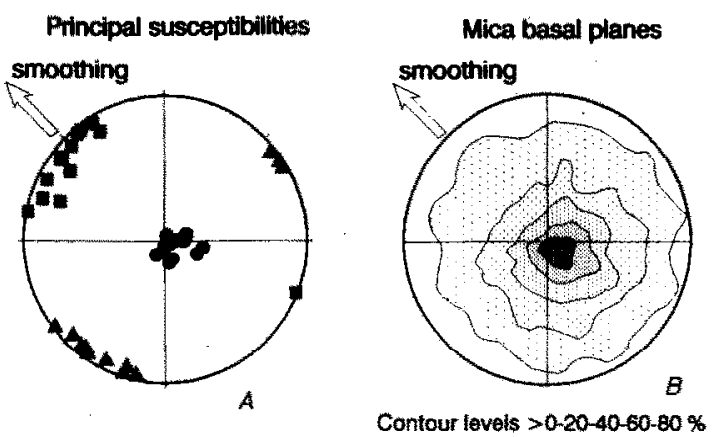

Fig. 5. Magnetic fabric and mica orientation of the samples prior to deformation. (A) The orientation of the principal susceptibility axes (squares $=k_{\max }$, triangles $=k_{\text {int }}$, circles $\left.k_{\text {min }}\right)$, the minimum axes are subvertical and the maximum axes scatter around the smoothing direction. (B) X-ray texture goniometry of mica (001) reflections (after Schrader, 1970) demonstrates coincidence between crystallographic lattice orientation and $\Lambda \mathrm{MS}$.

sion axis is represented by the minimum susceptibility axes. The initial orientation of the principal axes is nearly the same in all investigated samples. No influences of the mineral composition of the clay mixtures were evident.

\section{Magnetite-kaolin-water dispersions}

The magnetic fabrics of the undeformed and deformed magnetite bearing samples are shown in Fig. 6 and Table 1. The AMS magnitudes are represented in two Flinn-type diagrams to show their dependence on the magnetite content (Fig. 6A) and on the applied strain magnitude (Fig. 6B). The bulk susceptibility of the pure kaolin matrix is about $30 \times 10^{-6}$, whereas the susceptibility of the magnetite bearing samples is 10 to 100 times higher. Bulk susceptibility, hence, is influenced mainly by the magnetite and as a consequence the AMS is a function of the form and orientation of the magnetite grains. The magnetic fabric of the 1-\% magnetite bearing samples is almost entirely dominated by the magnetite. Although higher magnetite concentrations cause an increase in bulk susceptibility, the shape of the AMS ellipsoid is constant for all samples, and is therefore independent of magnetite content.

Microscopic investigation of the magnetite powder shows that the grains are sub-angular in 

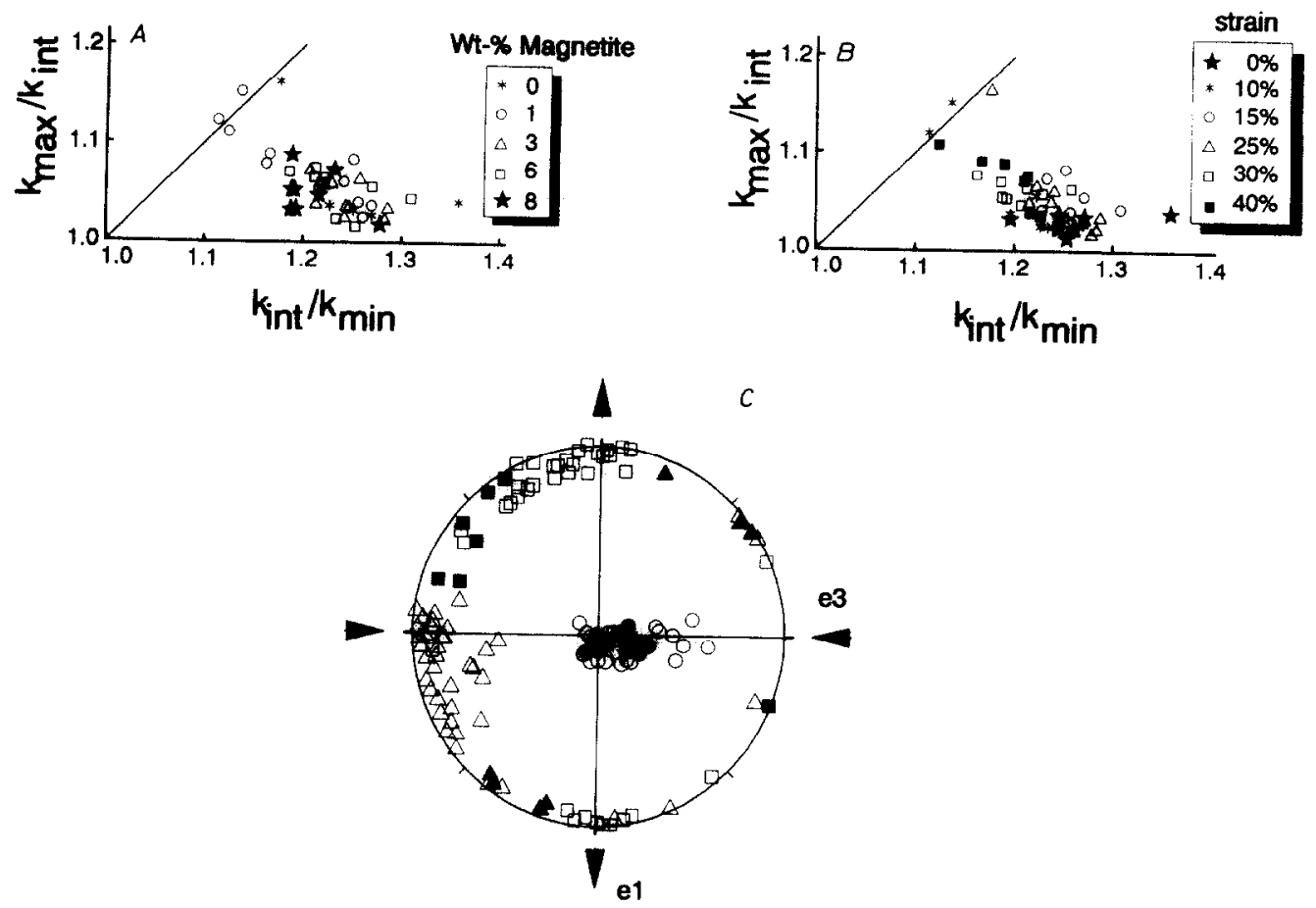

Fig. 6. Flinn-type diagrams of the magnetic fabric in the sample series magnetite-kaolin. The same values are plotted twice. All specimens are shown as (A) a function of their mineralogy and (B) of the applied strain magnitude. (C) Orientation of the principal susceptibility axes: filled symbols represent unstrained, initial fabric. Symbols as in Fig. 5 . The maximum axes rotate parallel to the extension direction; the minimum axes tend to rotate into the compression direction.

shape and randomly distributed. The shape dependence of AMS on magnetite causes a magnetic fabric that is determined by the magnetite mineral shape and orientation. Our experiments show that shape dependence and randomness of the initial fabric (which we could not control in our experiments) dominate the strain-induced magnetic fabrics. The degree of anisotropy of all

\section{TABLE 1}

The magnitudes of the principal susceptibilities from the kaolin-magnetite mixture series; values are volume susceptibilities in $\mathrm{SI} \times 10^{-6}\left(k_{1}=k_{\max } ; k_{2}=k_{\text {int }} ; k_{3}=k_{\min }\right)$

\begin{tabular}{|c|c|c|c|c|c|c|c|c|c|c|c|c|c|c|c|}
\hline \multirow[t]{2}{*}{$e_{1}$} & \multicolumn{3}{|c|}{ Kaolin } & \multicolumn{3}{|c|}{$1 \%$ magnetite } & \multicolumn{3}{|c|}{$3 \%$ magnetite } & \multicolumn{3}{|c|}{$6 \%$ magnetite } & \multicolumn{3}{|c|}{$8 \%$ magnetite } \\
\hline & $k_{1}$ & $k_{2}$ & $k_{3}$ & $k_{1}$ & $k_{2}$ & $k_{3}$ & $k_{1}$ & $k_{2}$ & $k_{3}$ & $k_{1}$ & $k_{2}$ & $k_{3}$ & $k_{1}$ & $k_{2}$ & $k_{3}$ \\
\hline 0 & 32 & 31 & 23 & 636 & 614 & 484 & 1413 & 1401 & 1098 & 3112 & 2975 & 2409 & 3658 & 3512 & 2895 \\
\hline 0 & & & & 648 & 633 & 503 & 1305 & 1273 & 1024 & 2997 & 2951 & 2355 & 3778 & 3651 & 3052 \\
\hline 10 & 29 & 28 & 22 & 639 & 555 & 489 & 1350 & 1279 & 1047 & 3285 & 3120 & 2519 & 3834 & 3742 & 3049 \\
\hline 10 & & & & 634 & 567 & 510 & 1454 & 1406 & 1129 & 3170 & 3096 & 2513 & 4144 & 3997 & 3344 \\
\hline 15 & 30 & 29 & 23 & 612 & 565 & 451 & 1417 & 1371 & 1098 & 3266 & 3095 & 2436 & 4220 & 4137 & 3235 \\
\hline 15 & & & & 623 & 600 & 478 & 1413 & 1407 & 1062 & 3118 & 2989 & 2283 & 4459 & 4151 & 3367 \\
\hline 25 & 34 & 29 & 25 & 658 & 621 & 501 & 1468 & 1421 & 1105 & 3312 & 3143 & 2581 & 4299 & 4108 & 3376 \\
\hline 25 & & & & 633 & 594 & 487 & 1433 & 1403 & 1095 & 3310 & 3160 & 2554 & 4034 & 3876 & 3158 \\
\hline 30 & & & & 536 & 497 & 428 & 1371 & 1297 & 1056 & 3328 & 3112 & 2622 & 3628 & 3445 & 2892 \\
\hline 30 & & & & 550 & 526 & 435 & 1543 & 1452 & 1154 & 2982 & 2804 & 2312 & 3816 & 3624 & 3045 \\
\hline 40 & 30 & 29 & 23 & 585 & 528 & 470 & 1369 & 1319 & 1086 & 2787 & 2631 & 2163 & 3643 & 3347 & 2815 \\
\hline 40 & & & & 543 & 499 & 428 & 1372 & 1281 & 1060 & 2873 & 2676 & 2207 & 3667 & 3391 & 2907 \\
\hline
\end{tabular}


magnetite bearing specimens, regardless of their deformation state, are summarized in Fig. 7. The mean value of all specimens is $1.293 \pm 0.035$. Figure 7 demonstrates that no relationship between the amount of magnetite and the AMS ellipsoid shape exists. Figure 7 also shows the mean $P$ values for the most deformed specimens. The weak positive correlation suggests that since all specimens have the same shape, magnetic interactions between prefercntially aligned magnetite grains occur.

Though the geometry of the AMS ellipsoids results from magnetite shape rather than from strain, the principal orientations of the susceptibility axes are strain intensity dependent (Fig. 6C). The AMS axes rotate into the principal strain directions probably due to a passive rotation of the magnetite grains in the clay-water dispersion (particulate flow, Borradaile and Tarling, 1981). After a $45^{\circ}$ rotation of the long grain axes, they reach parallelism with the extension direction after $40 \%$ shortening. The minimum axes of the angular shaped magnetites rotate into the $e_{3}$ direction, but do not reach parallelism.

\section{Illite-chlorite dispersions}

In Fig. 8 the magnitudes and directions of the magnetic measurements of the undeformed and deformed illite-chlorite mixtures are plotted. The

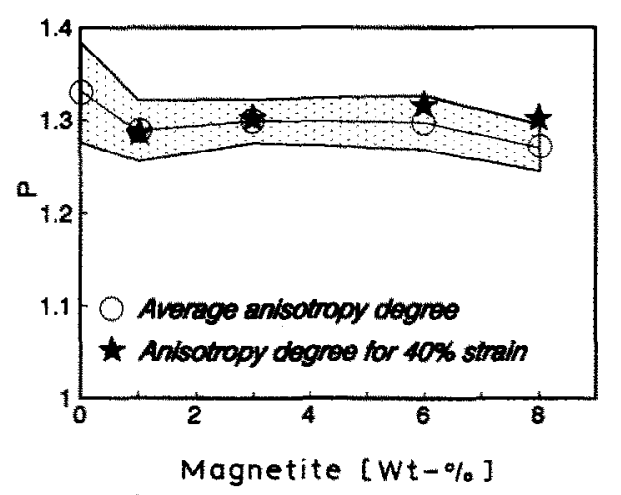

Fig. 7. A plot of the degree of anisotropy vs. the amount of magnetite in the kaolin matrix. The stippled area indicates the standard deviation $2 \sigma$. The AMS is unaffected by the magnetite concentration; the magnetic fabric is magnetite dominated. For the highest strains a positive correlation suggests magnetic interaction between preferentially aligned magnetites,
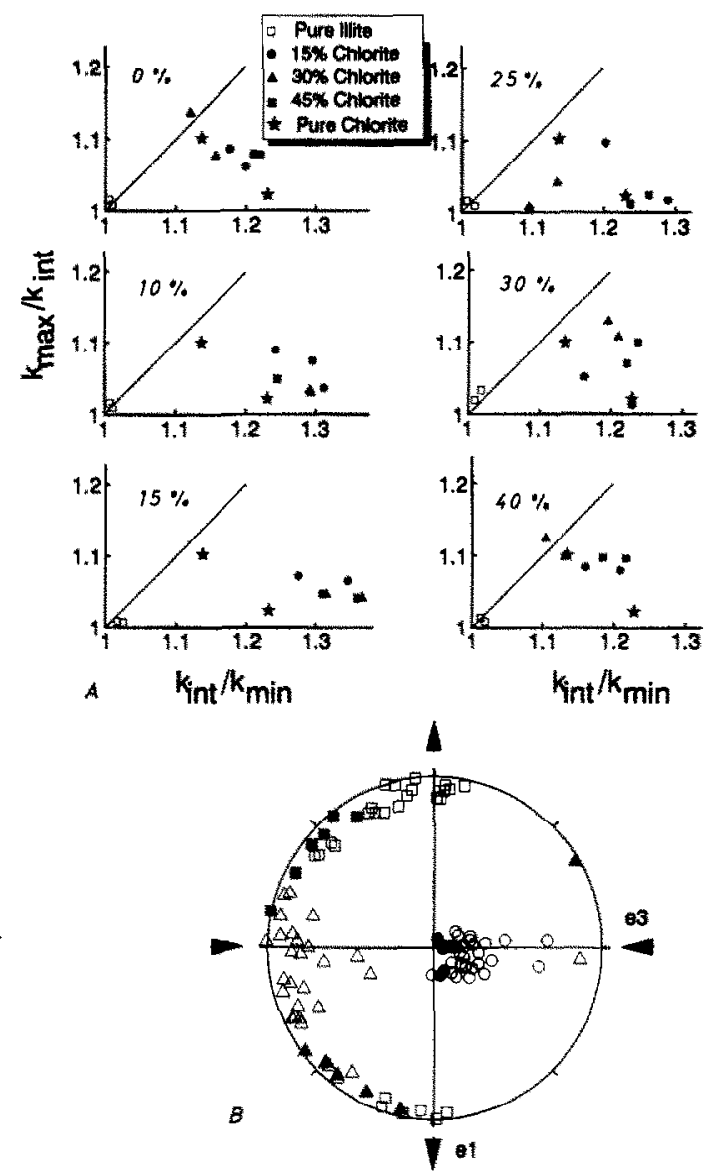

Fig. 8. (A) Flinn diagrams of the sample series illite-chlorite for various deformations. The quasi-isotropic illite contribution to the AMS was subtracted to obtain the magnetic fabric of the chlorite. The scatter is smallest for the highest deformation; pure chlorite data are from Borradaile et al, (1987). (B) Stereogram showing orientations of the principal susceptibility axes; symbols as in Fig. 5; filled symbols are unstrained reference samples. The maximum axes are parallel to the extension direction in the higher deformed samples.

principal AMS and strain magnitudes are given in Table 2. Figure $8 \mathrm{~A}$ shows all the specimens according to their mineral composition for different strain magnitudes in Flinn diagrams. The orientations of the principal susceptibility axes are given in Fig. 8B.

The pure illite specimens are quasi-isotropic (Fig. 8A). Regardless of the applied strain, the AMS ellipsoids plot near the origin of the Flinn diagram. The weak anisotropy of the pure illite specimens demonstrates, that the AMS of the mixtures is caused mainly by the chlorite minerals. We subtracted the illite part (using the mean 


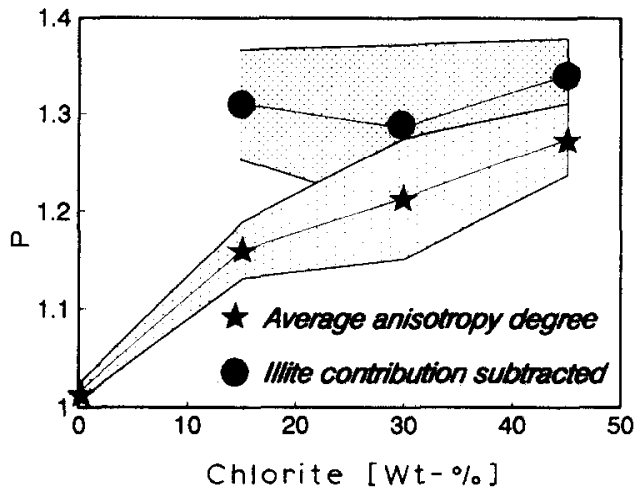

Fig. 9. A plot of the degree of anisotropy vs. the chlorite concentration in the illite matrix shows a positive correlation; the AMS magnitudes are mainly a function of the mineral concentration. The correlation disappears after subtraction of the contribution of the quasi-isotropic illite matrix. The stippled areas indicate the standard deviation $2 \sigma$.

susceptibility of illite multiplied by the percentage of illite present) from the AMS ellipsoids of the mixtures to obtain the chlorite fabric only (Fig. 8A). The AMS ellipsoid is oblate in most cases (Fig. 8A) and has a well-defined anisotropy with an average degree of anisotropy of $1.312 \pm$ 0.068 for the chlorite and $1.216 \pm 0.065$ for the illite-chlorite mixtures (excluding the pure illite). AMS values of single chlorites were obtained by Borradaile et al., (1987) and plotted in Fig. 8A for comparison. Their anisotropy is similar to the
AMS of the investigated illite-chlorite mixtures. In Fig. 9 the degree of anisotropy of all specimens is plotted versus the chlorite content. Despite the broad scatter, indicated by the standard deviation, a correlation between the amount of chlorite and the degree of anisotropy is obvious. This shows that the magnetic fabric, in contrast to the magnetite-kaolin mixtures, is not entirely dominated by the stronger susceptible mineral, but that the AMS of the mixtures is chiefly a function of the chlorite concentration. The variation of the degree of anisotropy disappears if the illite contribution is subtracted.

Though influences of strain on the magnitudes of the magnetic fabric are obliterated by mineral variations, strain causes the $k_{\max }$ axes to rotate in a position sub-parallel to the extension axis (Fig. $8 \mathrm{~B})$. As in the magnetite-kaolin mixtures, the minimum axes move towards the compression axis. No quantifiable correlation between the magnitudes of strain and the AMS shape exists. The magnitudes of the initial and final magnetic fabrics are almost identical. However, the scatter in the Flinn diagram is lowest for the highest strain. Directional and magnitude results are basically not different from the results obtained from the magnetite-kaolin series, although the reasons for the AMS (shape and magneto-crystalline anisotropy) are fundamentally different.

TABLE 2

Magnitudes of principal susceptibility axes of the illite-chlorite series

\begin{tabular}{|c|c|c|c|c|c|c|c|c|c|c|c|c|}
\hline \multirow[t]{2}{*}{$e_{i}$} & \multicolumn{3}{|l|}{ illite } & \multicolumn{3}{|c|}{$15 \% \mathrm{chl}$} & \multicolumn{3}{|c|}{$30 \% \mathrm{chl}$} & \multicolumn{3}{|c|}{$45 \% \mathrm{chl}$} \\
\hline & $k_{1}$ & $k_{2}$ & $k_{3}$ & $k_{1}$ & $k_{2}$ & $k_{3}$ & $k_{1}$ & $k_{2}$ & $k_{3}$ & $k_{1}$ & $k_{2}$ & $k_{3}$ \\
\hline 0 & 81.6 & 80.7 & 80.3 & 165.1 & 159.6 & 144.9 & 293.5 & 276.6 & 246.9 & 462,0 & 432.2 & 366.3 \\
\hline 0 & 83.8 & 83.6 & 83.1 & 157.5 & 150.5 & 138.7 & 301.8 & 272.8 & 249.6 & 440.0 & 411.9 & 347.3 \\
\hline 10 & 85.2 & 84.6 & 84.4 & 202.1 & 191.3 & 167.9 & 298.0 & 290.8 & 238.0 & 386.7 & 371.2 & 308.7 \\
\hline 10 & 85.2 & 84.8 & 84.4 & 197.6 & 193.3 & 164.2 & 270.5 & 263.7 & 217.2 & 397.9 & 374.1 & 301.1 \\
\hline 15 & 78.6 & 78.3 & 77.9 & & & & 303.7 & 287.9 & 241.2 & 399.7 & 384.6 & 306.6 \\
\hline 15 & 84.4 & 84.1 & 83.1 & & & & 331.6 & 315.6 & 252.8 & 448.8 & 433.3 & 333.1 \\
\hline 25 & 85.3 & 84.6 & 84.3 & 205.1 & 193.1 & 172.5 & 264.1 & 255.6 & 232.0 & 387.7 & 383.9 & 320.8 \\
\hline 25 & 86.6 & 86.1 & 85.1 & 186.1 & 184.3 & 158.9 & 243.8 & 242.6 & 226.5 & 393.7 & 385.4 & 316.3 \\
\hline 30 & 85.6 & 83.3 & 82.2 & 170.0 & 165.2 & 151.9 & 302.8 & 275.0 & 239.2 & 432.0 & 407.4 & 342.8 \\
\hline 30 & 86.6 & 85.4 & 85.1 & 176.0 & 174.6 & 155.2 & 304.4 & 280.6 & 241.9 & 457.6 & 421.2 & 350.5 \\
\hline 40 & 84.8 & 84.3 & 83.9 & 183.1 & 174.8 & 156.9 & 260.3 & 238.0 & 220.9 & 389.7 & 360.2 & 305.6 \\
\hline 40 & 85.6 & 84.9 & 84.1 & 178.5 & 170.1 & 156.4 & 261.8 & 243.5 & 222.0 & 360.8 & 333.7 & 290.2 \\
\hline
\end{tabular}




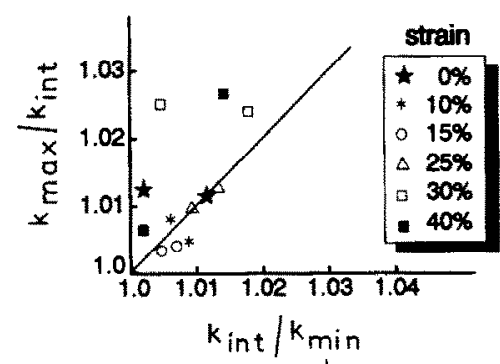

Fig. 10. The AMS shapes of the deformed and undeformed Keuper clay samples in a Flinn diagram. The anisotropy is very weak, a correlation between strain magnitude and AMS shape is not apparent.

\section{The Keuper clay and the pure illite samples}

The Flinn diagram (Fig. 10) shows the principal susceptibility magnitudes of the undeformed and deformed Keuper clay samples. The magnitudes are given in Table 3. The distribution of the AMS shapes and the very low degree of anisotropy $(P=1.02 \pm 0.01)$ indicate quasi-isotropic behavior.

Since the susceptibility of pure hematite is in the order of $10^{-3}$ up to $3 \times 10^{-2}$ (Uyeda et al., 1963) and the susceptibility of the hematite bearing Keuper clay is in the order of $83 \times 10^{-6} \mathrm{SI}$ units, paramagnetic and diamagnetic matrix minerals contribute dominantly to the bulk susceptibility and, hence, to the magnitudes of AMS. Despite the weak anisotropy, a distinct preferred orientation of the clay minerals due to sample preparation was imparted on the samples, as can

\section{TABLE 3}

AMS values from the Keuper clay

\begin{tabular}{rlll}
\hline$e_{1}$ & $k_{1}$ & $k_{2}$ & $k_{3}$ \\
\hline 0 & 45.3 & 44.8 & 44.3 \\
0 & 50.5 & 49.9 & 49.8 \\
10 & 69.4 & 69.1 & 68.5 \\
10 & 68.0 & 67.5 & 67.1 \\
15 & 54.2 & 54.1 & 53.8 \\
15 & 59.2 & 59.0 & 58.6 \\
25 & 54.7 & 54.1 & 53.4 \\
25 & 61.5 & 60.9 & 60.4 \\
30 & 54.6 & 53.3 & 53.0 \\
30 & 58.8 & 57.4 & 56.4 \\
40 & 59.8 & 59.5 & 59.4 \\
40 & 63.3 & 61.7 & 60.8 \\
\hline
\end{tabular}

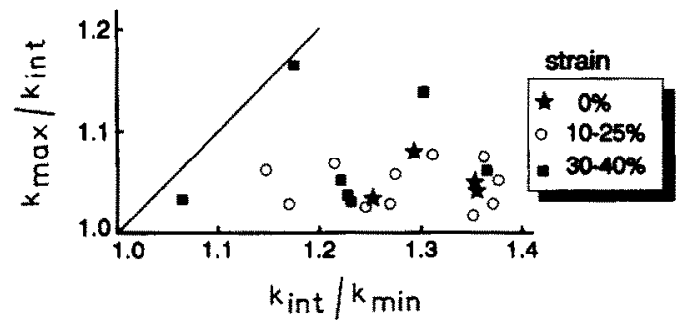

Fig. 11. Flinn diagram of the AMS data from the kaolin clay showing an almost strong oblate fabric and no apparent correlation to the imparted strain magnitude.

be seen from the orientation of the principal susceptibility axes (compare Fig. 5A for the initial fabric of all specimens).

The pure illite samples show the same characteristics. Weak anisotropies are in the order of $P=1.016 \pm 0.009$ and demonstrate a similar distribution pattern in the Flinn diagram as the Keuper samples. The AMS geometry was not noticeably affected by strain.

\section{The kaolin-water dispersions}

The Flinn diagram (Fig. 11) presents the AMS ellipsoid shapes and the orientation of the principal susceptibility axes of the kaolin-water systems. The principal AMS magnitudes are given in Table 1. Though the bulk susceptibility of this clay is low, which is partly due to the dilution effect of about $30 \%$ diamagnetic quartz, the anisotropy ellipsoid shape is comparable to the AMS attained from the kaolin-magnetite and illite-chlorite mixtures. The mean degree of anisotropy is in the order of $P=1.34 \pm 0.09$ and exceeds, in some cases, the values reached by the higher susceptible magnetite bearing samples (compare Fig. 7). Quartz thus affects the bulk susceptibility, but, since it is nearly isotropic (Hrouda 1986), has no marked effect on the magnitudes of the AMS. Figure 11 shows that the ellipsoid shape is not controlled by the deformation. The ellipsoid shape of all specimens is oblate. The principal directions of the AMS, due to the oblateness of the magnetic fabric, are poorly defined in the $k_{\max }-k_{\text {int }}$ plane. Minimum susceptibility is well defined in its initial orientation and reveals no apparent reorientation during straining. 


\section{Discussion}

A distinct initial magnetic fabric was imparted on all specimens prior to deformation. In all lithologies the maximum susceptibility parallels the extension axis and the minimum susceptibility was found to correspond to the compression axis. In Fig. 5B the orientations of mica (001) basal planes, as obtained from X-ray texture goniometry (Schrader, 1970), are shown together with the principal AMS orientations. The perfect parallelism between the maximum of (001) poles and the orientation of $k_{\min }$ shows the relation between the AMS and the crystallographic orientation of phyllosilicates. The clustering of the maximum susceptibility axes in the paramagnetic mixtures shows that a preferred orientation not only of the mica basal planes was acquired, but also of one of the crystallographic axes in the basal plane.

The initial magnetic fabric $\left[k_{i j}\right]_{\text {ini }}$ of the claywater dispersion is the resultant of the preferred orientation of grain shape (magnetite) or crystallographic lattice planes of all minerals and phases present. It is the sum of the single grain AMS tensors $\left[k_{i j}\right]_{g}$, neglecting weak influences of the diamagnetic and isotropic water:

$$
\begin{aligned}
{\left[k_{i j}\right]_{\mathrm{ini}} } & =\sum_{g=1}^{n}\left[k_{i j}\right]_{\mathrm{g}} \\
\quad(i, j & =1,2,3 ; n=\text { number of grains })
\end{aligned}
$$

The diagonal part of $\left[k_{i j}\right]_{\mathrm{ini}}$, its magnitude, thus is a function of the magnitude and orientation of each $\left[k_{i j}\right]_{\mathrm{g}}$ (single grain AMS), whereas the rotational part is determined only by the preferred orientation of the lattice planes and/or the shape axes.

$\left[k_{i j}\right]_{\text {ini }}$ is modified by straining the grain aggregate. This causes a particle motion which results in the rotation of $\left[k_{i j}\right]_{\mathrm{g}}$. Initial susceptibility thus transforms to the final susceptibility tensor $\left[k_{i j}\right]_{\text {fin }}$. The following quantitative relation between the strain tensor and the AMS tensor is assumed (Borradaile and Alford, 1988):

$\left[e_{i j}\right]\left[k_{i j}\right]_{\mathrm{ini}}=\mathbf{M}\left[k_{i j}\right]_{\mathrm{fin}}$

with $\left[e_{i j}\right]$ being the finite strain tensor and $\mathbf{M}$ a $(3 \times 3)$ matrix. This equation implies proportionality between strain and AMS. If the variations of the initial fabric $\left[k_{i j}\right]_{\text {ini }}$ exceed the influences of $\left[e_{i j}\right]$, as was demonstrated for the investigated samples, the final AMS is more or less a function of the initial fabric and influences of strain are not detectable.

The investigated materials are divided into three groups by different initial fabrics and strain response, although the fabric producing treatments were essentially the same for all samples:

(1) Mineral grains ("magnetic minerals") with magnetocrystalline anisotropy or shape anisotropy dispersed in a weakly susceptible matrix. The AMS behavior is controlled by the properties of the magnetic mineral in two ways. First, when the susceptibility ratio between the magnetic mineral and the matrix is extremely high (in the order of $10^{4}$ ), even small traces of less than $1 \%$ of the mineral are sufficient to dominate the AMS fabrics and influences of the matrix are completely overprinted. Secondly, for susceptibility ratios on the order of 10 , an interaction between the magnetic fabric and the mineral concentration exists, the resulting total AMS is a superposition of both constituents.

Due to passive rotation of the minerals in the matrix, the extensional axis and the maximum susceptibility axis approach parallelism during straining. Up to $45^{\circ}$ rotation of the long mineral axes occurred at $40 \%$ shortening. No difference between the behavior of shape anisotropic magnetites or lattice anisotropic chlorites is detected. The single mineral tensor $\left[k_{i j}\right]$ is random in the case of the magnetites. The initial fabric therefore is unpredictable and shape dependence of the magnetite AMS completely overprints strain induced magnetic fabrics. For this reason AMS is dominated by grain-shape and reveals limited correlation to strain. Nevertheless, a weak trend from an oblate ellipsoid shape to a "plane strain" form may exist. In most cases AMS was represented by an oblate ellipsoid.

(2) Clay-water dispersions (illite, Keuper clay) that are quasi-isotropic. The AMS shape is sometimes oblate and sometimes prolate. This is caused by random effects on the nearly isotropic mass during sample preparation. Nevertheless, the principal susceptibility directions of the initial fabric are well defined, although the scatter is 
broad. No effects of strain on the weak AMS magnitudes or directions are apparent. This behavior is produced by the dispersion of nearly equidimensional magnetocrystalline particles. A preferred orientation is acquired only from some illite-chlorite platelets whose shape coincides with the crystallographic lattice. Motion of these particles during straining could not produce a preferred orientation defined by the scarce mica flakes.

(3) Clays with a strongly oblate AMS that reveal no obvious strain response (kaolin). Oblateness of the magnetic fabric is caused by the preferred orientation of the flaky mica minerals. A significant strain induced reorientation of the mica basal planes did not occur, as can be concluded from the distribution of the susceptibility minimum poles.

Coarser and more susceptible minerals in a deformed dispersion tend to rotate with the long axes into the extensional direction causing a parallel orientation between $k_{\max }$ and the extension direction. This occurs more rapidly than the rotation of the short axis $k_{\text {min }}$ into the shortening direction. If no such mineral is present, a noticeable and reproducible effect of a later deformation on the well defined initial fabric was not observed. A correlation between applied strain and principal susceptibility magnitudes, however, in all cases is obliterated by variations in grain shape and mineralogical composition. AMS magnitudes did not reveal a correspondence to the strain magnitudes or the strain geometry.

In soft and lithified natural assemblages, the compositional scatter is even more uncontrolled, since the materials that compose a sediment were not crushed, sieved and weighed as in the laboratory experiments. Thus, slight variations of magnetite shape, chemical variations in the mica lattice, variations of the amount of different mincrals or even differences in grain size affect the total AMS. The origin of the magnetic fabric magnitudes, even from adjacent specimens, thus have to be carefully investigated before comparisons between strain magnitudes and AMS magnitudes are carried out.

Though the experiments do not show a strain response of the AMS geometry this does not imply that there is no influence of strain on the magnetic fabrics. The uncontrolled initial fabric is responsible for the apparent failure of a correlation between the magnitudes of AMS and strain. Deformed natural mudrocks therefore may preserve the principal directions of strain, but the AMS magnitudes can hardly be used for a comparison with strain magnitudes.

\section{Conclusions}

The investigation of the magnetic fabrics of undeformed and deformed clay-water dispersions of varying mineralogy demonstrates:

(1) The orientation of the principal susceptibility axes is independent of the mineral composition of the clay. The initial orientation is determined by the sample preparation. $k_{\min }$ is parallel to the shortening direction and $k_{\max }$ parallel to the extension direction.

(2) Parallelism between the magnetic fabric orientation and the principal strain axes was achieved during deformation (up to $40 \%$ shortening) by a passive rotation of minerals.

(3) The magnetic fabric directly reflects the preferred mineral orientation. The minimum susceptibility axes are parallel to the maximum density of mica basal planes.

(4) The magnitudes of the principal AMS axes are a function of the mineral composition of the samples. They are either related to the chlorite concentration or the shape and orientation of the magnetite grains.

(5) A correlation between the magnitudes of strain and the magnitudes of the AMS is obliterated by variations in the mineral composition and the initial magnetic fabric.

\section{Acknowledgements}

This paper presents parts of Carl Richters Ph.D. thesis completed at the University of Tübingen. H.J. Mauritsch, University of Leoben (Austria) allowed the use of his laboratory facilities for magnetic measurements. We thank Ben A. van der Pluijm, Bernie Housen, Susanne Borchert, and reviewers Graham Borradaile and an anonymous reviewer for constructive com- 
ments on the paper, and František Hrouda for helpful discussion. The study was supported by grants from the Land Baden-Württemberg, the Deutscher Akademischer Austauschdienst (DA$\mathrm{AD}$ ), and the Deutsche Forschungsgemeinschaft (DFG grant RI 576/1-1).

\section{References}

Borradaile, G.J., 1987. Anisotropy of magnetic susceptibility: rock composition versus strain. Tectonophysics, 138: 327329.

Borradaile, G.J., 1988. Magnetic susceptibility, petrofabrics and strain - a review. Tectonophysics, 156: 1-20.

Borradaile, G.J. and Alford, C., 1988. Experimental shear zones and magnetic fabrics. J. Struct. Geol., 10: 895-905.

Borradaile, G.J. and Mothersill, J.S., 1984. Coaxial deformed and magnetic fabrics without simply correlated magnitudes of principal values. Phys. Earth Planet. Inter, 35: 294-300.

Borradaile, G.J. and Puumala, M.A., 1989. Synthetic magnetic fabrics in a plasticene medium. Tectonophysics, 164: 73-78.

Borradaile, G.J. and Tarling, D.H., 1981. The influence of deformation mechanisms on magnetic fabrics in weakly deformed rocks. Tectonophysics, 77: 151-168.

Borradaile, G.J., Keeler, W., Alford, C. and Sarvas, P., 1987. Anisotropy of magnetic susceptibility of some metamorphic minerals. Phys. Earth Planet. Inter., 48: 161-166.

Channell, J., Heller, F. and Van Stuijvenberg, J., 1979. Magnetic susceptibility anisotropy as an indicator of sedimentary fabric in the Gurnigel Flysch. Eclogae Geol. Helv., 72: $781-787$

Chmelik, F.B., 1967. Electro-osmotic core cutting. Mar. Geol., 5: 321-325.

Chilingarian, G.V., 1981. Compactional diagenesis. In: A Parker and B.W. Sellwood (Editors), Sediment Diagenesis Nato ASI Series C: Mathematical and Physical Sciences, 115: 57-168.

Crimes, T.P. and Oldershaw, M.A., 1967. Paleocurrent determinations by magnetic fabric measurements on the Cambrian rocks of St. Tudwal's peninsula, North Wales. Geol. J., 5: 217-232.

Curray, J.R., Moore, D.G., Lawver, L.A., Emmel, F.J. Raitt, R.W., Henry, M. and Kieckhefer, R., 1979. Tectonics of the Andamau Sea and Burma. In: L. Watkins, L. Montadert and P.W. Dickerson (Editors), Geological and Geophysical Investigations of Continental Margins. Am. Assoc. Pet. Geol., Mem., 29: 189-198.

Dekkers, M.J., 1988. Some rockmagnetic parameters for natural goethite, pyrrhotite and fine-grained hematite. Geol. Ultraiectina, $51,231 \mathrm{pp}$.

Ellwood, B.B., 1982. Estimates of flow direction for calc-alcaline welded tuffs and paleomagnetic data reliability from anisotropy of magnetic susceptibility measurements: central San Juan Mountains, southwest Colorado. Earth Planet. Sci. Lett., 59: 303-314.
Ellwood, B.B., Hrouda, F. and Wagner, J.-J., 1988. Symposia on magnetic fabrics: introductory comments. Phys. Earth Planet. Inter., 51: 249-252.

Flinn, D., 1962. On folding during three-dimensional progressive deformation. Q. J. Geol. Soc. London, 118: 385-433.

Hirt, A.M., 1986. Paleomagnetic and magnetic anisotropy techniques applied to tectonically deformed regions. Ph.D. Thesis, ETH Zürich, 159 pp.

Hamilton, N. and Rees, A.I., 1971. The anisotropy of magnetic susceptibility of the Franciscan rocks of the Diabolo Range, Central California. Geol. Rundsch., 60: 1103-1124.

Hoeppener, R., Kalthoff, E. and Schrader, P., 196\%. Zur physikalischen Tektonik: Bruchbildung bei verschiedenen affinen Deformationen im Experiment. Geol. Rundsch., 59: $179-193$.

Hoeppener, R. and Schwarz, H.-U., 1980. Experimentelle Untersuchungen über Schiefergefüge und Gefüge in geschieferten Gesteinsverbänden. Neues Jahrb. Geol. Paläontol. Abh., 160: 363-379.

Hoeppener, R., Kalthoff, E. and Schrader, P., 1969. Zur physikalischen Tektonik: Bruchbildung bei verschiedenen affinen Deformationen im Experiment. Geol. Rundsch., 59: $179-193$.

Hounslow, M.W., 1985. Magnetic fabric arising from paramagnetic phyllosilicate minerals in mudrocks. J. Geol. Soc. London, 142: 995-1006.

Housen, B. and Van der Pluijm, B.A., 1990. Chlorite control of correlations between strain and anisotropy of magnetic susceptibility. Phys. Earth Planet. Inter., 61: 315-323.

Hrouda, F, 1982. Magnetic anisotropy of rocks and its application in geology and geophysics. Geophys. Surv, , 5: 37-82;.

Hrouda, F., 1986. The effect of quartz on the magnetic anisotropy of quartzite. Stud. Geophys. Geodet., 30: 39-45.

Hrouda, F., Stephenson, A. and Woltär, L., 1983. On the standardization of measurements of the anisotropy of magnetic susceptibility. Phys. Earth Planet. Inter., 32: 203-208.

Jelinec, V., 1981. Characterization of the magnetic fabric of rocks. Tectonophysics, 79: T63-T67.

Kent, D.V. and Lowrie, W., 1975. On the magnetic susceptibility anisotropy of deep-sea sediment. Earth Planet. Sci. Lett., 28: 1-12.

Kissel, C., Barrier, E. and Laj, C., 1986. Magnetic fabric in "undeformed" marine clays from compressional zones. Tectonics, 5: 769-781.

Kligfield, R., Owens, W.H. and Lowrie, W., 1981. Magnetic susceptibility anisotropy, strain, and progressive deformation in Permian sediments from the Maritime Alps. Earth Planet. Sci. Lett., 55: 181-189.

Kligfield, R., Lowrie, W. and Pfiffner, O.A., 1982. Magnetic properties of deformed oolitic limestones from the Swiss Alps: the correlation of magnetic anisotropy and strain. Eclogae Geol. Helv., 75: 127-157.

Mauritsch, H., Becke, M., Kropácek, V., Zelinka, T. and Hejda, P., 1987. Comparison of the hysteresis characteris- 
tics of synthetic samples with different magnetite and haematite contents. Phys. Earth Planet. Inter., 46: 93-99. Nye, J.F., 1985. Physical Properties of Crystals. Oxford Unversity Press, Oxford, 329 pp.

Owens, W.H. and Rutter, E.H., 1978. The development of magnetic susceptibility anisotropy through crystallographic preferred orientation in a calcite rock. Phys. Earth Planet. Inter., 16: 215-222.

Pearce, G.W. and Fueten, F., 1989. An intensive study of magnetic susceptibility anisotropy of amphibolite layers of the Thompson Belt, North Manitoba. Tectonophysics, 162: 315-329.

Rathore, J.S., 1979. Magnetic susceptibility anisotropy in the Cambrian slate belt of North Wales and correlation with strain. Tectonophysics, 53: 83-97.

Rathore, J.S., 1980. The magnetic fabrics of some slates from the Borrowdale volcanic group in the English Lake District and their correlations with strains. Tectonophysics, 67: 207-220.
Rees, A.I., Von Rad, U. and Shepard, F.P., 1968. Magnetic fabric of sediments from the La Jolla submarine canyon and fan, California. Mar. Geol, 6: 145-178.

Ruf, A.S., Naruk, S.J., Butler, R.F. and Calderone, G.J., 1988. Strain and magnetic fabric in the Santa Catalina and Pinaleno mountains metamorphic core complex mylonite zones, Arizona. Tectonics, 7: 235-248.

Schrader, P., 1970. Bruchbildung in Modellsubstanzen durch Deformation mit monokliner Symmetrie. Ph.D. Thesis, Bochum, 86 pp.

Schieber, J. and Ellwood, B.B., 1988. The coincidence of macroscopic paleocurrent indicators and magnetic lineation in shales from the Precambrian Belt basin. J. Sediment. Petrol., 58: 830-835.

Tarling, D., 1983. Paleomagnetism. Chapman, London, 379 pp.

Uyeda, S., Fuller, M.D., Belshé, J.C. and Girdler, R.W., 1963. Anisotropy of magnetic susceptibility of rocks and minerals. J. Geophys. Res., 68: 279-291. 